\title{
Doctors feeling adrift as sea change sweeps US medicine
}

Y

ou'd think this would be a fine time to practise medicine in the United States.

A steady march to universal health insurance is about to bring some 30 million uncovered Americans in from the health care cold. The government is backing a battery of medical reforms with money that is scarce elsewhere in the federal budget. And science has opened opportunities for healing barely imagined a decade ago.

So why all the grumbling?

An ambitious survey of physicians has found discontent at almost every turn.

Doctors see their clinical autonomy eroding, their regulatory and liability responsibilities rising and pressure intensifying to do more, faster, with government and insurance companies looking over their shoulder. Nonclinical paperwork consumes the equivalent of one of every five workdays and constitutes their leading beef with the state of the profession (www.physiciansfoundation.org /uploads/default/Physicians_Foundation _2012_Biennial_Survey.pdf).

Altogether, more than half of the 13575 doctors who participated in the Physicians Foundation survey said they plan to cut back on seeing patients, work part-time, switch to cash-based concierge medicine, retire or take other steps that would reduce patient access to their services in the next one to three years.

"It pretty much adds up to burnout," says Phillip Miller, vice president of corporate communications for Merritt Hawkins in Irving, Texas. The firm, which conducted the foundation's study, is part of AMN Healthcare, the largest medical care staffing organization in the country.

The study provides snapshots of a profession in flux, as more doctors flee private practice to work for hospitals or physician organizations and President Barack Obama's health care law begins to take hold.

One clear trend is the decline of the solo practitioner, once the mainstay of American medicine.

Another, says the study, is that physicians are seeking ways to disengage from today's medical practice environment,

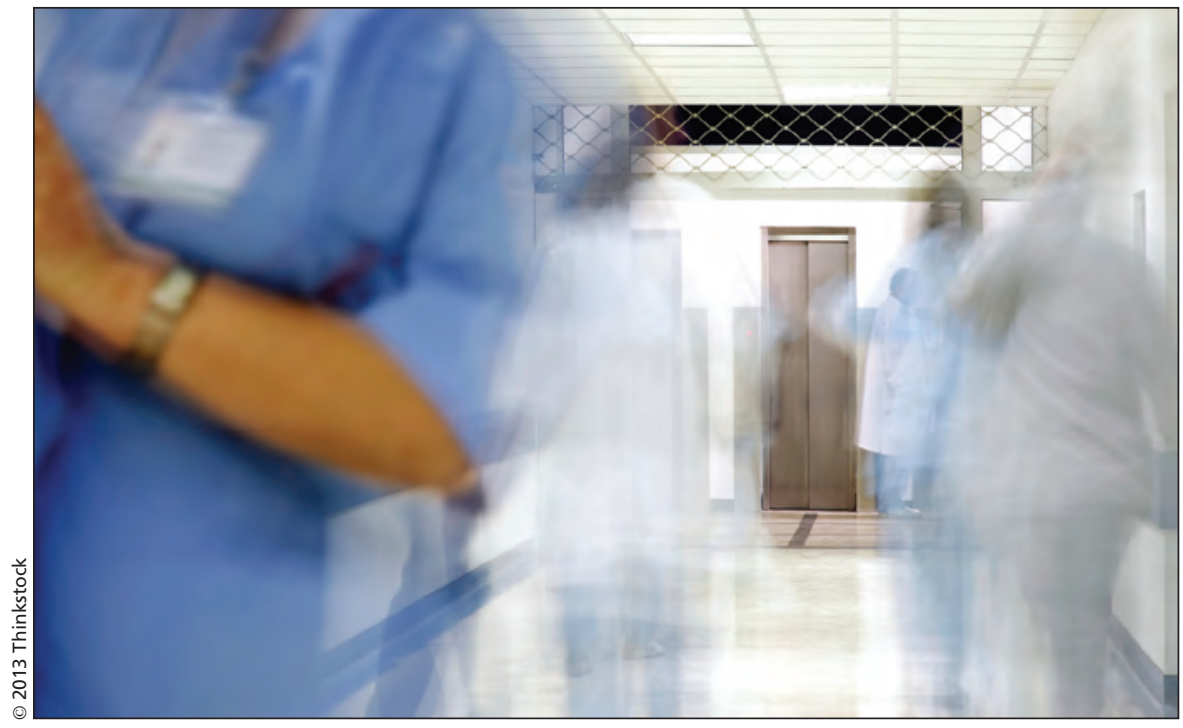

American physicians say they are under pressure to do more, faster, with government and insurance companies looking over their shoulder.

which "should be of urgent concern to both policy makers and the public."

Among the findings:

- Physicians are seeing nearly $17 \%$ fewer patients each day than in 2008.

- More than $62 \%$ of physicians estimate they provide at least $\$ 25000$ worth of uncompensated care every year.

- More than $72 \%$ of practising physicians are 40 years of age or older, and older male doctors are strikingly more pessimistic about the state of medicine than are younger doctors and female doctors.

- More than one-quarter of physicians have shut their practices to Medicaid patients and more than half intend to limit the access that Medicare patients have to their practices, or already have. Medicaid is government-paid health care for the poor; Medicare is the federal universal health insurance program for the elderly.

- One-third of practising physicians and more than half of new medical students are female, putting women on track to become the majority of the nation's physicians in a generation.

- More than $82 \%$ of physicians believe doctors have little ability to change the health care system.

- The Canadian single-payer model appeals to the young more than the old, but is not popular overall. In the survey, nearly half of physicians viewed Canada's system negatively as a solution for US health care, whereas one-third had a positive opinion.

There's no question that big changes are coming to US medicine and professionals are figuring out how to adapt.

For one, physicians are being encouraged, if not compelled, to move away from the traditional fee-for-service compensation system to one based on "value." The aim is to reward doctors for practising effectively and efficiently instead of for packing in patients and costly procedures.

That's jarring to many longestablished physicians, Miller says. "They started in a fee-for-service world. The horse kind of got switched mid-stream on them."

Younger doctors, though, are more accustomed to having their work evaluated, more drawn to innovation and, not surprisingly, more energetic and idealistic, he says. That helps to explain why they see their careers in more positive terms.

Regardless of age, says Miller, medical professionals are being forced to ask themselves how they can do things differently. "Say what you will about Obamacare, but it focuses the mind." - Cal Woodward, Washington, DC

CMAJ 2013. DOI:10.1503/cmaj.109-4448 